\title{
Job Displacement and the Transitions to Re-Employment and Early Retirement for Non-Employed Older Workers ${ }^{1}$
}

\author{
Konstantinos Tatsiramos \\ IZA
}

December 19, 2008

\begin{abstract}
Despite the relatively higher frequency of job displacement among older workers in Europe, little is known about its effect on the work-retirement decision. Employing individual data from the European Community Household Panel for a number of countries with differences in their institutional environments, the effect of job displacement for non-employed workers is identified separately for the transitions into re-employment and retirement. The findings suggest that in countries with relatively more generous unemployment insurance provisions for the older unemployed, which offer a pathway to early retirement, older displaced workers exhibit lower reemployment and higher retirement rates compared to the non-displaced. These results are robust to dynamic selection due to unobserved heterogeneity and to the endogeneity of displacement.
\end{abstract}

Keywords: Job Displacement, Unemployment Duration, Retirement, Institutions JEL Classification: J14; J26; J63; J64

\footnotetext{
${ }^{1}$ I would like to thank the two anonymous referees and the editor for their very useful comments. The paper has also benefited from comments and discussions with Ana Rute Cardoso, Daniel Hamermesh, David Jaeger, Michael Rosholm, Gerard van den Berg, Jan van Ours, Ralf Wilke and the participants at the ESEM Conference in Budapest, seminars at Concordia, the MILLS Seminar in Milano and University College Dublin, the Netspar workshop on Ageing, Pensions and Retirement in Utrecth, the IZA/SOLE Transatlantic Meeting in Ammersee, the IZA Prize Conference in Berlin and the IZA workshop on Heterogeneity in Micro Econometric Models in Bonn. The financial support provided through the European Community's Human Potential Programme under contract HPRN-CT-2002-00235, Economics of Ageing in Europe [AGE], is greatly acknowledged. Address of correspondence: IZA, Schaumburg-Lippe-Str. 5-9, 53113 Bonn, Germany. email: tatsiramos@iza.org
} 


\section{Introduction}

This paper investigates how job displacement which leads to non-employment affects the transitions into re-employment and retirement in a competing-risks hazard framework for a number of European countries which face different institutional rules. In recent years, there has been evidence of an increase in the frequency of job loss among older workers both in the U.S. (Farber et al., 1997; Farber, 2004) and in Europe (OECD, 1998). ${ }^{2}$ Despite this development, which has been associated with demand shifts, restructuring of traditional industries, import competition and outsourcing of jobs, surprisingly very little is known on how job displacement might affect the labour market transitions of older workers and, in particular, the work-retirement decision. Understanding the link between job displacement and retirement has direct implications for policies promoting longer working lives. These policies are considered in response to the decline in the labour force participation of older workers and the demographic changes occurring in Europe, which put pressure on the sustainability of the social security systems.

In theory, the direction of the effect of job loss towards re-employment or retirement is ambiguous. Experiencing a job loss may have considerable consequences because of the interruption of a long tenure job, which diminishes acquired firm-specific human capital, employment and earning prospects. Indeed, studies focusing on workers of all ages find that job displacement leads to a reduction of future earnings (Jacobson et al., 1993; Ruhm, 1991) and an increase of employment instability (Stevens, 1997) in the sense that the displaced have higher exit rates from subsequent employment. ${ }^{3}$ Although the unemployment rate among workers 45 to 64 years old is lower than the overall rate in most OECD countries, the incidence of long-term unemployment is significantly higher (OECD, 1998), which suggests a lower mobility of older workers who experience unemployment. Considering retirement as a distinct labour market state

\footnotetext{
${ }^{2}$ In what follows, job loss and job displacement will be used interchangeably.

${ }^{3}$ For a survey on the effect of job displacement see Kletzer (1998). Kuhn (2002) contains an analysis of work displacement for prime age workers for a number of European countries.
} 
allows for the distinction between two competing explanations for the incidence of long-term unemployment among older workers. That is, unemployment persistence might exist due to 1) difficulties in being re-employed based on poor employment prospects, or 2) disincentives of being re-employed. In a number of countries, the combination of extended unemployment benefit periods with early retirement schemes available for the older workers might affect their decisions by making retirement more attractive (Duval, 2003). ${ }^{4}$

However, job displacement might also affect the work-retirement decision in the opposite direction and reduce wealth and income, which might lead to an extension of the working life. Focusing on the transitions between non-employment and employment following a late-career job loss in the U.S., Chan and Stevens $(1999,2001)$ find that job loss for men leads to longer labour force participation, which reflects the need to rebuild diminished savings for retirement. For women, the reduced earnings due to a job loss reduce the incentives to work. Using Austrian administrative data, Ichino et al. (2007) find that after a plant closure the old initially have lower reemployment probabilities compared to prime-age workers, but later they catch-up.

The analysis in this paper has three novel and important features. The first is the focus on the distinction between transitions towards re-employment and retirement for older workers in a number of countries (Germany, Italy, Spain and the U.K.), which differ in their institutions related to older unemployed, based on individual panel data from the European Community Household Panel (ECHP, 1994-2001). In this respect, the paper contributes to relatively recent literature on the incentive effects of unemployment related benefits for older workers. Heyma and van Ours (2005) find that the abolition of the requirement to actively search for a job beyond the age of 57.5 and the entitlement to unemployment benefits until the age of 65 has a large negative effect on the job finding rate in the Netherlands. Other studies have shown that increases in the entitlement period of unemployment benefits for older workers leads to declines in transition rates to employment in

\footnotetext{
${ }^{4}$ The literature on retirement focuses on the incentive structure of the pension systems in explaining the observed retirement patterns (e.g. Gruber and Wise, 1998; Meghir and Whitehouse, 1997). Rigidities in the labour market, such as the inability to choose flexible working hours, might also lead to early withdrawal from the labour force even if older workers might prefer to retire gradually (Hurd, 1996).
} 
Germany (Hunt, 1995) and Austria (Lalive and Zweimüller, 2004), and provide a quantitatively important pathway into early retirement (Lalive, 2008). Kyyrä and Wilke (2007) evaluate the increase in the eligibility age from 53 to 55 of the unemployment insurance system in Finland, which allows unemployed workers to collect benefits up to a certain age limit and then retire. They find evidence of a large decrease in the inflow to unemployment and a large increase in the transition rate out of unemployment to employment.

The second novel feature of the paper is the joint estimation of the effects of job displacement on the transitions into and out of subsequent employment, distinguishing between the short and long-run effects of displacement. That is, although displaced workers might be re-employed relatively fast, it is also the stability of the post-displacement employment which is important for the overall employment rate. In addition, dynamic selection is taken into account by allowing unobserved individual characteristics to be correlated across states.

Finally, the paper addresses the endogeneity of displacement by extending the econometric model into a joint estimation of the selection process into displacement and the transitions into employment or retirement. Based on the "timing of the events" approach of Abbring and van den Berg (2003), the causal effect of displacement is identified by means of the variation from the multiple non-employment and employment spells which are observed for each individual.

The rest of the paper is organised as follows. Section 2 contains a brief discussion of the institutional features related to unemployment insurance and retirement rules in each of the countries considered in this study. Section 3 describes the data and provides a non-parametric analysis of labour market transitions. Section 4 presents the econometric model and discusses identification and the way to address the endogeneity of displacement. Section 5 discusses the results of the effect of displacement on labour market transitions, and the last section provides a summary of the findings and some policy conclusions. 


\section{Institutional Features}

The focus of this section is on the institutions which are related to older unemployed in the four countries considered in the analysis. These refer to the unemployment benefit and early retirement schemes based on information obtained from the Mutual Information System on Social Protection (MISSOC, 2001) of the European Commission. Tables A1 and A2 summarise the major policy instruments in each country, distinguishing between provisions that are available to the general public from those which are only available to older workers.

In Germany, the legal retirement age is 60 after 180 contribution months if unemployed at the commencement of the pension and if unemployed for 52 weeks after the age of 58.5. Alternatively, the requirement for older workers is to have worked part time for 24 calendar months. The age limit for early retirement for the unemployed increased in the years 1997 to 2001 from 60 to 65 years. However, a pension can be claimed after the age of 60 but with pension reductions. The replacement rate for unemployment benefit recipients is 67 per cent of net earnings (60 per cent for beneficiaries without children). The duration of benefits is 32 months for workers aged 54 and over.

In Spain, there is no direct provision of early retirement for the unemployed. However, early retirement is possible at the age of 60 with an $8 \%$ reduction for every anticipated retirement year. With respect to benefits for the older unemployed, workers are entitled under the Industrial Restructuring law to a form of benefit financed under the relevant restructuring plan. These benefits are of particular significance for workers aged at least 55 at the time of restructuring, who may draw them until they reach 65 years of age. The replacement rate for unemployment insurance recipients is 70 per cent for the first 180 days and 60 per cent thereafter. The duration of unemployment benefits received varies between 4 months and 2 years depending on the contribution period over the preceding 6 years. For the long-term unemployed aged 45 or more, there is a special 6 month benefit of 75-125 per cent of the minimum wage.

In Italy, there are no special benefits for the older unemployed with the possibility of early retirement. The legal retirement age is 63 for men and 58 for women. Early retirement is available 
from the age of 54 and after 35 years of contributions, or after 36 years of contributions regardless of age. Early retirement is possible for employees of companies in economic difficulty at the latest 5 years before normal retirement age. The replacement rate for the ordinary unemployment benefits is $30 \%$ of the average pay received during the last 3 months, and the duration is 180 days. The replacement rate for the special unemployment benefit for those in the building industry is $80 \%$ of previous earnings, with a duration of 90 days.

Finally, there are no provisions of early retirement in the U.K. and no benefits related to the older unemployed. The standard unemployment insurance rate is a flat rate of about 80 euros per week if aged 25 or over, with a duration up to 12 months, which was limited to 182 days in any jobseeking period in October 1996.

To summarise, institutions in Germany and Spain are designed to assist older unemployed and displaced; whereas such provisions are generally not available in Italy and the U.K.. It is worth mentioning that this does not preclude special schemes with incentives for early retirement, for instance, in Italy. However, these are case-specific and do not have a general applicability.

\section{Stylised Facts and Data}

Figure 1 depicts some stylised facts on the recent patterns in unemployment and displacement for workers by age. The left graph shows the unemployment rate for workers aged 16-50 and 50-64 in EU-15 countries for the period 1995-2007. The first fact to notice is the lower unemployment rate for older workers, although they face higher incidence of long-term unemployment (OECD, 1998). There are two peaks in the unemployment rate observed in 1997 and in 2004, with a decline in between, which is faster for the younger workers. The right graph shows the displacement rate as a percentage of employment. The risk of displacement is higher for the older workers and exhibits two peaks (in 1997 and 2004), while for the younger workers, we observe a declining rate from 1995 until 2001. Overall, displacement affects older workers proportionally more, and for the time 
period that this paper considers (1994-2001), the unemployment and the displacement rates exhibited their highest values.

The analysis of the effect of displacement on the labour market transitions of older workers is based on individual data from the European Community Household Panel (ECHP, 1994-2001). The ECHP is a survey based on a standardised questionnaire with annual interviews of a representative panel of households and individuals from the population in each country, and it covers a wide range of topics including demographics, employment characteristics, education, etc. In the first wave, a sample of some 60,500 nationally representative households - approximately 130,000 adults aged 16 years and over - were interviewed in the then 12 member states. There are three characteristics that make the ECHP relevant for this study: the simultaneous coverage of employment status; the standardised methodology and procedures yielding comparable information across countries; and the longitudinal design in which information on the same set of households and persons is gathered.

The ECHP contains monthly information for every individual in each wave on the labour market status during the previous year, distinguishing between unemployment, inactivity, employment and retirement. An inflow sample of the non-employed is constructed from all individuals 45 to 64 years old at the time of the first interview who respond in at least two consecutive years of the survey. The inflow sample consists of those who exit employment entering into either unemployment or inactivity (those who are not looking for a job but are not retired). Each non-employment spell can end by either returning to employment or retiring. Missing values of the monthly labour market status are imputed following Blau and Riphahn (1999) when the missing months are less or equal to three. ${ }^{5}$ The analysis allows for multiple non-employment spells.

\footnotetext{
${ }^{5}$ The missing information is replaced with the value of the month before the missing information when the values are the same before and after the missing month. With different values, the imputation depends on the number of missing months. Missing information is replaced with the value of the month after the missing month when the missing month is only one. With two missing months, the first missing value is replaced with the value of the previous month and the second missing value is replaced with the value of the next month. With three missing values, the first missing month is replaced with the value of the previous month, while the other two missing months are replaced with the value of the month after the missing months.
} 
Table 1 contains statistics of the sample by country. The inflow sample of individuals used in the analysis consists of those who are observed making a transition from employment into nonemployment. These numbers vary from 559 individuals for Italy to 904 for Germany (row 1), while the number of spells varies from 781 for the U.K. to 1801 for Spain (row 2). After dropping those spells with missing information on displacement, the remaining samples consists of 1064 spells for Germany, 765 for Italy, 1561 for Spain and 717 for the U.K. The last part of Table 1 shows the number of individuals in the data that are observed making a direct transition from employment to retirement by age groups. Compared to the number of spells entering into non-employment, the direct spells to retirement are relatively few and are not considered further in the analysis because retirement is an absorbing state. Hence, the focus of the analysis is on the transitions out of nonemployment.

\section{[Table 1 about here]}

Table 2 presents the transitions that occur in the sample. Non-employment spells might end either into employment or in retirement. The spells for which no transitions out of non-employment are observed until the end of the sample period are treated as right censored. About 50 per cent of the non-employment spells in Germany, and 65-68 per cent in Italy, Spain and the U.K., end in returning to employment. The share of spells which end in retirement is about 7 per cent for Italy, Spain and the U.K.; whereas it is much higher - about 20 per cent - for Germany. For those being re-employed, 58 per cent make a transition back to non-employment in Germany, about 75 per cent in Italy and Spain, and 45 per cent in the U.K. ${ }^{6}$ Finally, transitions from employment to retirement after having experienced a non-employment spell vary from 2.8 per cent in Spain to 6.2 per cent in the U.K.

\section{[Table 2 about here]}

\footnotetext{
${ }^{6}$ The paper focuses on Germany, Italy, Spain and U.K. As for the other countries in the ECHP, the inflow sample was relatively small resulting in very few transitions, especially towards retirement. As the focus of the paper is on the distinction between transitions to re-employment and retirement, this selection was inevitable. However, as discussed in section 2, the four countries studied offer interesting variations in institutional characteristics, each representing different welfare regimes.
} 
For each of the non-employment spells an indicator of displacement is constructed using the information on the reason for leaving the previous job. The displaced are defined as those who were obliged to leave their previous job by the employer. Table 3 shows the frequency distribution of the reasons for job loss. The share of spells that are defined as involuntary separations (displaced workers) because they were obliged to stop their work by the employer varies from 49.2 per cent in Germany to 31 per cent in Italy, and about 18 per cent in Spain and the U.K. For the non-displaced workers, the most important reason for ending employment is the end of a contract. For Spain, the share of employment spells which end in non-employment for this reason is close to 58 per cent, which is not surprising given the high usage of temporary contracts, followed by Italy (42 per cent) and Germany (24 per cent). The most common reason for leaving the previous job in the U.K. is to obtain a better or more suitable job (about 40 per cent).

\section{[Table 3 about here]}

Table 4 presents summary statistics of individual characteristics by displacement status. Except for Germany, older individuals with medium education are more likely to be displaced. For the other characteristics, no clear pattern seems to exist across countries. Table 4 also presents summary statistics for the spells that are dropped due to missing information on the reason for leaving the previous job, which are used for constructing the displacement dummy. The individuals that are dropped due to missing information are on average somewhat older, with lower education in Germany and Italy and higher education in Spain and the U.K., and worse health in Germany, Spain and the U.K. ${ }^{7}$

\section{[Table 4 about here]}

The advantage of using survey data compared to administrative data is that the sample is more representative of the whole population of displaced workers. With administrative data, displacement is defined using information on plant closures which excludes all involuntary job separations that

\footnotetext{
${ }^{7}$ Overall, although some differences appear in the average characteristics between the included and the missing spells in terms of age, education and health, there is no evident systematic pattern across the groups of countries (Germany and Spain versus Italy and the U.K.) which might be driving the results.
} 
occur on an individual basis. Moreover, with survey data, a control group can be defined out of those who voluntarily left their previous job (for a better job, marriage, childbirth, looking after others, illness, etc.). However, using survey data has the disadvantage of relying on self-reported information for the reason of job separation, which might be correlated with individual unobserved characteristics or be endogenous to labour market institutions. For instance, quits might be reported as layoffs for the worker to be eligible for unemployment insurance, or layoffs reported as quits to avoid the administrative burden on the side of the employer in countries with strict employment protection legislation. In addition, even in the case of plant closure, the workers who remain until the plant closes are selected non-randomly from the group of workers who were present when the firm's initial negative demand shocks arrived. This occurs as the firm learns which employees are likely to quit and alters its layoff policies accordingly (Pfann and Hamermesh, 2001). ${ }^{8}$

\subsection{Empirical Hazard Estimates}

Figure 2 shows the proportion of non-employed who re-enter employment by displacement status. The cumulative failure is based on the empirical (Kaplan-Meier) hazard rates and is equal to one minus the survival rate. In Germany, Italy and Spain, non-displaced workers return to employment faster than those displaced; while the opposite is true for the U.K. One possible reason for the higher re-employment of displaced workers in the U.K. might be the high share of workers who left their previous job to obtain a better or more suitable job, as shown in Table 2. These workers are classified as non-displaced and are expected to stay unemployed longer until they find a better match.

[Figure 2 about here]

Figure 3 shows the cumulative failure from non-employment to re-employment for the displaced by age groups. In Germany and Spain, there is a big difference across age groups in the proportion of displaced workers who return to employment. While for those aged 45-54 more than 60 per cent

\footnotetext{
${ }^{8}$ The way to address the endogeneity of displacement is discussed in Section 4.1.
} 
eventually return to employment, it is only about 40 per cent of those older displaced (aged 55-64) that are re-employed. Such differences by age are smaller for Italy and the U.K.. These figures suggest that displacement past a certain age (around 55 years old) is not "repaired" for workers in Germany and Spain.

\section{[Figure 3 about here]}

Figure 4 depicts the proportion of workers who exit subsequent employment. It shows that among the non-employed workers in all countries who are re-employed, those who have entered into nonemployment due to displacement exhibit a lower exit rate.

[Figure 4 about here]

Although differences in re-employment and subsequent employment hazards between displaced and non-displaced are useful, they are not informative on the transitions towards other states, and in particular, retirement. Moreover, such differences might be confounded by individual observed and unobserved characteristics or dynamic selection, which might arise as workers with higher employability are expected to leave non-employment faster and obtain more stable employment. To address these issues, an adequate econometric model is required.

\section{Econometric Methodology}

The econometric analysis is based on a multivariate mixed proportional hazard model. In line with most applications analysing individual's labour market transitions, a reduced-form approach is adopted (see van den Berg (2001) for an overview of duration models).

\subsection{The Statistical Model}

The analysis considers the effect of job loss on the transitions from non-employment ( $n e$ ) and from subsequent employment $(e)$ for those who are re-employed. Non-employed workers have the following options: accept a job offer and be re-employed $(n e-e)$, or retire $(n e-r)$. The transitions from non-employment to employment or retirement are modelled in a competing-risks framework. 
The transitions from subsequent employment are modelled as a single-risk due to the lack of a sufficiently large sample that would allow a distinction to be made between re-entering unemployment and retiring. Observations for individuals who remain non-employed until the end of the observation period are treated as right-censored.

Each hazard function is the product of the baseline hazard, $\lambda_{j i}^{s}\left(t_{k}\right)$, which captures the time dependence of the hazard rate and the systematic part, $\exp \left(y_{j i k}^{s}\right)$, which shifts the baseline hazard and is defined as

$$
\theta_{j i k}^{s}\left(t_{k} \mid \varepsilon_{j i}^{s}\right)=\lambda_{j i}^{s}\left(t_{k}\right) \exp \left(y_{j i k}^{s}\right)
$$

where $i$ refers to the individual, $j=n e, e$, and $k$ denotes the spells for each individual.

For the non-employment spells, where $j=n e$, the index $y_{j i k}^{s}$ is defined as

$$
y_{\text {neik }}^{s}=\beta_{0 n e}^{s}+\beta_{1 n e}^{s} X_{n e i k}+\delta_{1 n e}^{s} D_{k}+\sum_{a=1}^{3} \delta_{2 n e}^{s} I(a) D_{k}+\varepsilon_{n e i}^{s}
$$

while for the employment spells $y_{e i k}$ is defined as

$$
y_{e i k}=\beta_{0 e}+\beta_{1 e} X_{e i k}+\delta_{1 e} D_{k}+\sum_{a=1}^{3} \delta_{2 e} I(a) D_{k}+\varepsilon_{e i}
$$

Note that for the non-employment hazard in (2), there are two destination states which are denoted with the superscript $s=e, r$, and the coefficients are destination specific. For the employment hazard, $s$ denotes just a single state, so it is dropped from (3).

The main variable of interest is the dummy variable $D_{k}$ denoting whether a non-employed worker has been displaced. The specification includes a set of interactions of the displacement dummy with age dummies denoted as $I(a)$. Given sample size constraints, three age groups are considered: 45-54 $(a=1), 55-60(a=2)$ and 61-64 $(a=3)$. The systematic part includes also individual characteristics and economic variables denoted as $X_{j i k}$. The observed characteristics refer to the year in which each spell started and are fixed within a spell. However, they are allowed to vary across non-employment and employment states and across multiple spells for each 
individual. The variables include age dummies, education dummies (defined using the ISCED classification), whether the individual is married, the number of children, non-labour income based on capital and property income acting as a proxy for wealth and a homeownership dummy. ${ }^{9}$ The economic variables include the regional unemployment rate at the time of entering non-employment or employment, respectively. ${ }^{10}$ The baseline hazard has a semi-parametric representation using a piece-wise constant function with specified month intervals for 1-6 months of duration, for 7-12 months, for 13-24 months and for more than 24 months.

In order to account for the endogeneity of displacement, the model is extended to a joint estimation of the selection process in displacement and the transitions out of non-employment and employment. The selection process, which is specified as a logit model, is defined as

$$
P=\operatorname{Pr}\left(D_{k}=1 \mid X_{i k}, \varepsilon_{d}\right)=\Lambda\left(y_{d i k}\right)
$$

where $y_{d i k}=\beta_{0 d}+\beta_{1 d} X_{d i k}+\varepsilon_{d i}$, and $d$ denotes the displacement selection equation. This procedure for dealing with endogenous regressors in a duration framework is analogous to the study by Bover et al. (2002), who consider a univariate model of unemployment duration, and to the treatment of initial conditions by Ham and LaLonde (1996) in their evaluation of training on a multivariate model of unemployment and employment spells.

Combining the contributions of the completed spells to re-employment, retirement and subsequent employment, and the censored spells and selection process in equation (4), the total contribution to the likelihood for each individual can be written as

$$
L_{i}^{p}=L_{n e} L_{e} \Lambda^{d}(1-\Lambda)^{1-d}
$$

\footnotetext{
${ }^{9}$ Questions about job tenure are asked in the ECHP on a yearly basis (at the time of each interview) and not each month. Since the spells are based on a monthly calendar, the tenure variable includes many missing values, thus reducing the sample considerably. Therefore, it is not included in the regressors. Controlling for unobserved heterogeneity enables the effect of tenure to be captured, as individuals with higher employability are more likely to obtain a good job match and experience longer job tenure.

${ }^{10}$ Year dummies are also included which capture wide economic effects and the effect of policy changes (e.g. Germany). Given the data limitation, an investigation of the effect of policy changes is left for future research based on administrative data.
} 
where $L_{n e}$ and $L_{e}$ are the likelihood contributions for the non-employment and employment spells, respectively. ${ }^{11}$

Following Heckman and Singer (1984), the unobserved heterogeneity distribution is defined as a discrete distribution with the support points denoted by $\left(\varepsilon_{n e, p}^{e}, \varepsilon_{n e, p}^{r}, \varepsilon_{e, p}, \varepsilon_{d, p}\right)$ and the corresponding probability mass given by $\operatorname{Pr}\left(\varepsilon_{n e}^{e}=\varepsilon_{n e, p}^{e}, \varepsilon_{n e}^{r}=\varepsilon_{n e, p}^{r}, \varepsilon_{e}=\varepsilon_{e, p}, \varepsilon_{d}=\varepsilon_{d, p}\right)=\pi_{p}$, where $P$ denotes the number of support points. Each unobserved factor is assumed to be time-invariant and individual-specific for each destination state. That is, it is assumed to be the same across multiple spells of non-employment or employment. However, the unobserved factors are allowed to be different and correlated across non-employment and employment spells. The joint distribution $G\left(\varepsilon_{n e}^{e}, \varepsilon_{n e}^{r}, \varepsilon_{e}, \varepsilon_{d}\right)$ contains an additional component $\varepsilon_{d}$, which captures the effect of unobserved factors that affect the probability of being displaced and can be correlated with the transition equations. The sample likelihood can be written as follows

$$
L=\prod_{i=1}^{n} \sum_{p=1}^{P} \pi_{p} L_{i}^{p}
$$

where the individual likelihood $L_{i}^{p}$ is defined in (5).

\subsection{Identification}

The purpose of the econometric model is to identify the causal effect of displacement on the transitions out of non-employment and subsequent employment. The model includes a competingrisks part which distinguishes between transitions from non-employment to employment, or retirement. Identification of a competing-risks proportional hazard model has been shown by Heckman and Honore (1989). In the multivariate duration model, which includes the transitions out of subsequent employment, dynamic selection is controlled for by allowing the unobserved

\footnotetext{
${ }^{11}$ The likelihood contributions for the transitions are defined in detail in Tatsiramos (2007).
} 
characteristics to be correlated across the non-employment and employment spells. A detailed discussion of such dynamic selection can be found in the study by Ham and LaLonde (1996).

The identification of the displacement effect (treatment) relies on the identification of treatment effects on duration models by Abbring and van den Berg (2003). Using the variation and randomness in the timing of the treatment, and controlling for selection into treatment based on unobservables, they show that the causal treatment effect is identified without the need of exclusion restrictions. The assignment into treatment embeds a competing-risks model that does not involve the treatment. Empirical applications which exploit the "timing of events" approach can be found in Bonnal et al. (1997), Abbring et al., (2005), Lalive et al. $(2005,2008)$ and van den Berg et al. (2004).

For the purpose of this paper, the assignment into treatment is reduced to the probability model in (4), in which the probability of being displaced is defined as

$$
\operatorname{Pr}\left(D_{k}=1\right)=\frac{\theta_{d}}{\theta_{d}+\theta_{q}}
$$

where $\theta_{d}$ and $\theta_{q}$ denote the probability of exiting the previous employment due to displacement or quitting, respectively. Identification of this model relies on observing multiple non-employment and employment spells for each individual, which provide variation on the displacement indicator. As with the linear panel data, observing multiple outcomes for given unobserved heterogeneity values can be exploited to deal with unobserved heterogeneity under conditions that are mild, relative to the single-spell case (Abbring and van den Berg, 2003). By allowing unobserved heterogeneity in the selection equation to be correlated with the transition equations, the selection effect is identified separately from the causal effect of the treatment. As an example of such selection, one can think of individuals who are more likely to be displaced and simultaneously less likely to be re-employed because of unobserved differences in their labour market attachment.

Identification is also based on two assumptions related to anticipation and announcement effects. The non-anticipation assumption requires that individuals do not adjust their behaviour 
inducing displacement by knowing the future retirement date. The announcement effect is related to the situation in which agents, knowing about a future job loss in advance, might retire immediately or might postpone any action and retire after being laid off. The dependence of pension benefits on employment and earnings in the years before retirement or the requirement for a number of years of contributions for pension eligibility reduces the incentives of retiring earlier in the case of the announcement effect. Moreover, modelling the probability of being displaced conditional on observed and unobserved characteristics and allowing this probability to be correlated with the transitions to re-employment or retirement captures the selection that might occur in the case of inducing or postponing displacement due to announcement and anticipation effects.

\section{Empirical Results}

The econometric model is estimated under three different sets of assumptions. The first assumes that there is no unobserved heterogeneity, so transitions across states are independent and displacement is also exogenous. The second allows for correlated unobserved heterogeneity treating displacement as exogenous, while the third relaxes both assumptions of independent transitions and the exogeneity of displacement. Each of these models is also estimated by including interactions of the displacement dummy with age groups in order to capture age dependent effects of displacement on the transitions across labour market states.

\subsection{The Effect of Displacement}

Table 4 presents the coefficient estimates for the displacement dummy and for duration dependence from the model without controlling for individual unobserved heterogeneity, assuming displacement is exogenous. Estimates from the first panel for the transitions from non-employment to employment show that displaced workers in Germany, Italy and Spain are significantly less likely to be re-employed compared to the non-displaced. The effect of being displaced is positive, but not significant for the U.K.. The second panel of Table 4 for the transitions from non- 
employment to retirement shows that displaced workers in Italy and the U.K. are less likely to retire compared to the non-displaced. The effect is significant at the 5 per cent level only for Italy. On the other hand, individuals in Spain who have been displaced are significantly more likely to retire. The third panel of Table 4 shows the coefficient estimates for the transition out of subsequent employment. The coefficients of displacement exhibit a negative sign in all of the countries, but they are not significantly different from zero. These estimates under the independence assumption suggest that the non-employed workers who have been displaced seem to face lower probabilities of being re-employed, while the effect of displacement on the retirement decision is rather mixed: positive for Spain; negative for Italy and the U.K.; and zero for Germany.

\section{[Table 5 about here]}

Duration dependence is negative and significant in all countries for the transitions to reemployment and positive for the transitions to retirement. ${ }^{12}$ That is, individuals that stay longer in non-employment enter both employment and retirement later. However, in the presence of unobserved individual characteristics, such as motivation or unobserved human capital variables, the coefficient estimates of the effect of displacement and duration dependence are expected to be downward biased. The reason is that dynamic selection occurs, as those with high values of the unobserved variables have higher exit rates on average. Hence, the remaining sample of individuals who are still non-employed at high durations tend to have lower values of the unobserved variables. This leads to spurious duration dependence and to a lower observed difference in the hazards between displaced and non-displaced than the true average difference. The latter happens as the sample of non-displaced survivors, who have a higher hazard, has on average lower values of the unobserved variables than the sample of displaced survivors.

Taking into account unobserved heterogeneity, the results in Table 5 show a similar pattern for the effect of displacement as with the model in which the transitions are assumed to be

\footnotetext{
${ }^{12}$ Since a constant is included in the model, the first interval is normalised to zero, so the reference category in the duration dependence coefficients is duration between 1 to 6 months.
} 
independent. The effect is larger, indicating a downward bias if unobserved heterogeneity is ignored, and a comparison of the likelihood values reveals an improvement in the fit of the model.

[Table 6 about here]

In the empirical application with two points of support for each of $\varepsilon_{n e}^{e}, \varepsilon_{n e}^{r}$, and $\varepsilon_{e}$, and an unrestricted correlation, the empirical results implied perfect correlation. Hence, the model is estimated under perfect correlation between the error terms. The first mass point is normalised to zero for identification, as there is a constant term in the vector of covariates so the second mass point can be interpreted as the deviation from the first. Therefore, six parameters are identified and one probability. This means, conditional on the observed characteristics and the time spent in the current spell, there are two types of individuals which differ in their non-employment hazard (high/low) towards re-employment and retirement and their employment hazard (high/low). The heterogeneity mass points indicate the presence of one group in Italy and Spain with a lower hazard towards re-employment and out of subsequent employment, and a higher hazard towards retirement. For Germany and the U.K., the heterogeneity distribution seems to affect mostly the transitions out of subsequent employment. Finally, the pattern of duration dependence is also similar between the two models, although the effect is smaller in the model with unobserved heterogeneity, which is expected due to the dynamic selection discussed above.

\subsection{The Effect of Displacement by Age}

To investigate the extent in which the displacement effect differs by age, the displaced dummy is interacted with age groups as described in (2) and (3) of Section 4.1. Specification 2 in Table 7 refers to the case in which the displaced dummy is interacted with the age groups 45-54 and 55-60, so the main effect refers to the displaced above 60 years old. The cut-off points of the age groups at 55 and 60 are chosen, so that they match the institutional features as closely as possible, as

described in section 2. For instance, workers aged 55 and above in Germany can claim unemployment benefits for a longer period of time, and they can retire if unemployed at the age of 
60. In Italy, workers can retire at 55 after 35 years of contributions. At the same time, these cut-off points allow for sufficient variation for the estimation of the model. With the existing data, it is not possible to perform the estimation with interactions of the displacement dummy with each age, so broader age groups need to be defined.

The first step in the analysis is to investigate the main effects of age both for the displaced and the non-displaced. The coefficient estimates from Table 7 suggest that younger workers (aged 4554) are more likely to be re-employed and less likely to retire compared to the workers above 60 in all countries. This evidence is consistent with the observed patterns from a number of countries that older workers experience longer non-employment periods (Kuhn, 2002; OECD, 1998). This might reflect that older workers are less adaptable to change than younger workers or that, due to specific occupation and industry skills, they experience fewer job opportunities and might spend longer searching for a job. The higher transition to retirement for older workers is also consistent with evidence of higher labour force withdrawal.

The role of institutions, such as unemployment benefits and provisions for retirement, is also important and might produce differential effects across countries. In Germany, for instance, the reemployment probability for workers aged 55-60 is lower and the retirement probability is higher. This can be explained by the increased generosity of the unemployment benefits system for workers within this age group and the eligibility for early retirement at 60 if unemployed for 52 weeks after reaching the age of 58.5 years. Therefore, unemployed workers in this age group seem to face incentives, due to the institutional structure, to postpone re-employment until they become eligible for early retirement. This postponement effect can explain the negative coefficient for the reemployment probability for the age group 55-60. For Italy, we also observe a higher retirement probability for non-employed workers 55 years old and above. This seems to be related to the provision for retirement at age 55 after 35 years of contribution.

[Table 7 about here] 
The next step is to consider whether differential age effects exist for displaced workers. For the younger age group (45-54), there is a small negative effect of being displaced on the transitions to re-employment. For Germany and Spain, this negative effect of displacement on re-employment is higher for the older displaced (55+) compared to the non-displaced. In addition, displaced workers more than 60 years old in these two countries exhibit a significant higher transition to retirement. These findings suggest that the institutional arrangements which provide relatively more generous unemployment benefits for the older unemployed, with the possibility of early retirement at age 60 for the insured unemployed, affect the behaviour of the displaced workers differentially from the non-displaced creating disincentives of being re-employed before becoming eligible for early retirement at around 60 .

Older displaced in Italy - above 55 years old - are less likely to exit non-employment towards both re-employment and retirement. ${ }^{13}$ That is, contrary to Germany and Spain, an increased exit rate of older displaced workers towards retirement is not found for Italy. Finally for the U.K., being displaced does not seem to have a significant effect on the exit rate from non-employment, either towards re-employment or retirement.

\subsection{Results with Endogenous Displacement}

The discussion so far is based on the assumption that displacement is exogenous and uncorrelated to unobserved heterogeneity. However, workers might decide to quit instead of being laid-off due to an announcement effect, or there might be unobserved characteristics that make them more likely to be laid-off than others. The extent to which these characteristics also affect their transitions across labour market states might lead to biased estimates. Table 8 shows the estimates for the transitions from non-employment to employment or retirement and the transitions out of subsequent employment for both specifications (for the overall displacement effect and by age).

\footnotetext{
${ }^{13}$ Both effects are larger for the age group 55-60.
} 
For Germany and Spain, even after accounting for the endogeneity of displacement, older displaced are less likely to be re-employed and more likely to exit to retirement. The effect towards retirement is significant and positive for Germany in specification 2, which refers to the displaced above 60 years old. For Spain, a positive effect is also found, although the effect is not as precisely estimated as in the model, without taking into account the endogeneity of displacement. For Italy and the U.K., displaced workers do not differ in their likelihood of being re-employed compared to the non-displaced in specification 1. While for the U.K. these results are similar to the ones in Table 7, taking into account the endogeneity of displacement changes the negative and significant effect for Italy to a positive, but insignificant, one. As for the transitions to retirement, displaced workers in these two countries are less likely to exit to retirement.

\section{[Table 8 about here]}

Overall, these results show that there are clearly two different patterns on the effect of displacement. In Germany and Spain, displaced workers exhibit lower re-employment and higher retirement rates compared to the non-displaced. To the contrary, the re-employment rates in Italy and the U.K. do not differ between the two groups of workers, but the displaced exhibit lower transitions rates towards retirement. These patterns suggest a role of the different institutions which prevail across countries. The availability of unemployment related benefits (in Germany and Spain) offers a pathway to early withdrawal from the labour market, which coincides with longer unemployment spells.

Regarding the transitions out of subsequent employment, Table 8 shows differences in the effect of displacement compared to the model in which displacement is assumed to be exogenous. In particular, the effect is negative and significant for displaced workers in Germany. This is consistent with the potential beneficial effect of relatively more generous benefits on the subsequent employment stability, as workers have the time to obtain a more suitable job (Tatsiramos, forthcoming). To the contrary, previously displaced workers in Spain and Italy are significantly more likely to exit their subsequent employment spell. Without allowing for correlation in the 
unobserved determinants of the displacement probability and the transitions, the effect is negative. The distribution of unobserved heterogeneity shows, for Italy and Spain in particular, the presence of a group with a lower propensity to experience displacement and higher transitions into and out of employment. Due to data limitations, it is not possible to distinguish whether these subsequent transitions are directed towards re-entering unemployment or exiting to retirement. Possible reasons for these higher exit rates from subsequent employment might be the use of fixed term contracts in Spain and the provision for retirement at age 55 after 35 years of contribution in Italy. That is, a displaced worker might have an incentive - in the absence of generous benefits - to find a job in order to reach the minimum contribution years for becoming eligible for retirement.

Finally, Table 9 shows the transition specific coefficient estimates of specification 1 for the individual characteristics including the ones for the equation of the probability to be displaced. As expected, being young and educated increases the likelihood of being re-employed. Experiencing health problems appears to lower the chances of re-employment, while the number of children lowers the transitions to retirement.

\section{[Table 9 about here]}

\section{Conclusion}

The labour market situation of older workers has become extremely important in recent years. Population ageing is expected to increase the share of older workers in the labour force, and displacement due to technological progress and restructuring of traditional industries disproportionately affects older workers. Despite these developments, very little is known on how job displacement might affect the work-retirement decision. This paper investigates the effect of job displacement for workers 45-64 years old on the labour market transitions in Germany, Italy, Spain and the U.K., based on individual data from the European Community Household Panel (ECHP, 1994-2001). To understand the factors and the incentives that determine the behaviour of older workers, a multivariate competing-risks hazard model is estimated which considers the transitions out of non-employment to re-employment and retirement. Explicitly modelling the transitions to 
retirement allows for the distinction between two competing explanations for the low reemployment rates of older displaced workers. That is, difficulties of being re-employed versus the lack of incentives of being re-employed if unemployment can be used as a pathway to early retirement. The model also distinguishes between the short and long term effects of job loss by analysing the transitions from the post-displacement employment state, taking into account correlated unobserved heterogeneity and the endogeneity of displacement.

The results suggest that there are differential effects of displacement by age. In particular, non-employed workers in Germany and Spain are less likely to be re-employed if they are displaced when they are above 55 years old, and they are more likely to retire after 60 compared to the nondisplaced. In contrast, the older displaced in Italy and the U.K. are less likely to exit to retirement. Institutional differences across countries might explain these findings. In particular, the relatively generous unemployment insurance for involuntary unemployed in Germany and Spain, with the possibility of retiring as early as 60 years old, might create incentives not to return to employment for those below the age of 60 , and for an early withdrawal from the labour market for those above 60. In contrast, the lack of generous unemployment benefits and early retirement provisions for the displaced in countries such as Italy and the U.K. seem not to create incentives for an early exit from the labour force. Instead, displaced workers return to employment faster than the non-displaced, although this effect is not statistically significant.

These findings suggest that the institutional environment is not only important, but it produces differential effects on the behaviour of older workers. This has important policy implications for the necessary reforms in response to the demographic changes occuring in Europe, and the pressures they place on the social security systems. In particular, policies aiming at increasing the employment rates of older workers should take into account the higher frequency of job displacement among older workers and the role of labour market institutions that affect their reemployment probabilities. Efforts to lower the incidence of job displacement among older workers and increase their re-employment probabilities are interrelated through the institutional design. As 
suggested by Blanchard and Tirole (2008) unemployment insurance and employment protection should be designed jointly rather than in isolation. Severance payments linked to the wage profile of workers can lower the incidence of job displacement, while unemployment insurance being conditional on looking for and accepting available jobs can simultaneously reduce the disincentive effect of unemployment insurance and thus increase job finding rates. 


\section{References}

Abbring, J.H., van den Berg, G.J., 2003. The Nonparametric Identification of Treatment Effects in Duration Models. Econometrica 71(5), 1491-1517.

Abbring, J.H., van den Berg, G.J., van Ours, J.C., 2005. The Effect of Unemployment Insurance Sanctions on the Transition Rate from Unemployment to Employment. The Economic Journal, 115(505), 602-630.

Blanchard, O.J., Tirole J., 2008. The Joint Design of Unemployment Insurance and Employment Protection: A First Pass. Journal of the European Economic Association, 6(1), 45-77.

Blau, D.M., Riphahn, R.T., 1999. Labour Force Transitions of Older Married Couples in Germany. Labour Economics, 6(2), 229-252.

Bonnal, L., Fougère, D., Sérandon, A., 1997. Evaluating the Impact of French Employment Policies on Individual Labour Market Histories. Review of Economic Studies, 64, 683-713.

Bover, O., Arellano, M., Bentolila, S., 2002. Unemployment Duration, Benefit Duration and the Business Cycle. The Economic Journal, 112(479), 223-265.

Chan, S., Stevens, A.H., 1999. Employment and Retirement Following a Late-Career Job Loss. The American Economic Review, 89(2), 211-216.

Chan, S., Stevens, A.H., 2001. Job Loss and Employment Patterns of Older Workers. Journal of Labor Economics, 19(2), 484-521.

Duval, R., 2003. The Retirement Effects of Old-age Pension and Early Retirement Schemes in OECD Countries. OECD Economics Department Working Paper 370, OECD.

Farber, H.S., Haltiwanger J., Abraham, K.G., 1997. The Changing Face of Job Loss in the United States, 1981-1995. Brookings Papers on Economic Activity, Microeconomics, 55-142.

Farber, H.S., 2004. Job Loss in the United States, 1981-2001. Research in Labor Economics 23, 69-117.

Gruber, J., Wise D., 1998. Social Security and Retirement: An International Comparison. American Economic Review, 88(2), 158-163.

Ham, J.C., LaLonde R.J., 1996. The Effect of Sample Selection and Initial Conditions in Duration Models: Evidence from Experimental Data on Training. Econometrica, 64(1), 175205.

Heckman, J.J., Singer, B., 1984. A Method of Minimizing the Distributional Assumptions in Econometric Models for Duration Data. Econometrica, 52(2), 271-320.

Heckman, J.J., Honore B.E., 1989. The Identifiability of the Competing Risks Model. Biometrika, 76(2), 325-330.

Heyma, A., van Ours, J.C., 2005. How eligibility criteria and entitlement characteristics of unemployment benefits affect job finding rates of elderly workers. Mimeo.

Hunt, J., 1995. The Effect of Unemployment Compensation on Unemployment Duration in Germany. Journal of Labor Economics, 13(1), 88-120.

Hurd, M.D., 1996. The Effect of Labor Market Rigidities on the Labor Force Behavior of Older Workers. In: Wise, D.A. (Ed.), Advances in the Economics of Aging, University of Chicago Press, pp. 11-58. 
Ichino, A., Schwerdt, G., Winter-Ebmer, R., Zweimüller, J., 2007. Too Old to Work, Too Young to Retire? IZA Discussion Paper, No. 3110.

Jacobson, L.S., LaLonde, R.J., Sullivan, D.G., 1993. Earnings Losses of Displaced Workers. The American Economic Review, 83(4), 685-709.

Kletzer, L.G., 1998. Job Displacement. Journal of Economic Perspectives, 12(1), 115-136.

Kuhn, P. J., 2002. Losing Work, Moving on: International Perspectives on Worker Displacement. W.E. Upjohn Institute of Employment Research, Kalamazoo, Michigan.

Kyyrä, T., Wilke R.A., 2007. Reduction in the Long-Term Unemployment of the Elderly: A Success Story from Finland. Journal of the European Economic Association, $5(1), 154-182$.

Lalive, R., 2008. How do Extended Benefits affect Unemployment Duration? A Regression Discontinuity Approach. Journal of Econometrics, 142(2), 785-806.

Lalive, R., van Ours, J.C., Zweimüller, J., 2008. The Impact of Active Labor Market Programs and Benefit Entitlement Rules on the Duration of Unemployment. Economic Journal, 118, 235-257.

Lalive, R., van Ours, J.C., Zweimüller J., 2005. The Effect of Benefit Sanctions on the Duration of Unemployment. Journal of the European Economic Association, 3(6), 13861417.

Lalive, R., Zweimüller, J., 2004. Benefit Entitlement and Unemployment Duration: The Role of Policy Endogeneity. Journal of Public Economics, 88(12), 2587-2616.

Meghir, C., Whitehouse E., 1997. Labor Market Transitions and Retirement of Men in the UK. Journal of Econometrics, 79(2), 327-354.

MISSOC, 2001. Social Protection in the Member States of the European Union. European Commission, Directorate-General for Employment Industrial Relations and Social Affairs.

OECD, 1998. Work-force Ageing in OECD Countries. OECD Economic Outlook, chapter IV.

Pfann, G.A., Hamermesh D.S., 2001. Two-Sided Learning, Labor Turnover and Worker Displacement. IZA Discussion Paper No. 308.

Ruhm, C.J., 1991. Are Workers Permanently Scarred by Job Displacements? The American Economic Review, 81, 319-324.

Stevens, A.H., 1997. Persistent Effects of Job Displacement: The Importance of Multiple Job Losses. Journal of Labor Economics, 15(1), 165-188.

Tatsiramos K., 2007. The Effect of Job Displacement on the Transitions to Employment and Early Retirement for Older Workers in Four European Countries. IZA Discussion Paper, No. 3069.

Tatsiramos K., forthcoming. Unemployment Insurance in Europe: Unemployment Duration and Subsequent Employment Stability. Journal of the European Economic Association.

van den Berg, G.J., 2001. Duration Models: Specification, Identification, and Multiple Durations. In: Heckman, J.J., Leamer E.E. (Eds.), Handbook of Econometrics, vol V, North Holland, pp. 3381-3460.

van den Berg, G.J., van der Klaauw, B., van Ours, J.C., 2004. Punitive Sanctions and the Transition Rate from Welfare to Work. Journal of Labor Economics, 22(1), 211-241. 